\title{
A PROBLEMATIZAÇAO DOS DIREITOS DO CLIENTE IMPLICANDO NA PROBLEMATIZAÇÃO DOS DIREITOS DOS PROFISSIONAIS DE ENFERMAGEM
}

\author{
CUSTOMER'S RIGHTS PROBLEMATIZATION IMPLYING NURSING \\ PROFESSIONALS' RIGHTS PROBLEMATIZATION
}

\author{
LA PROBLEMATIZACIÓN DE LOS DERECHOS DEL CLIENTE ENLAZADOS \\ CON LA PROBLEMATIZACIÓN DE LOS DERECHOS DE LOS PROFESIONALES \\ DE ENFERMERIA
}

NARCISO VIEIRA SOARES* e VALÉRIA LERCH LUNARDI**

\begin{abstract}
RESUMO
A partir da constatação na prática cotidiana de múltiplas situações de desrespeito aos direitos do cliente, desenvolveu-se uma prática educativa com o objetivo de problematizar os direitos do cliente, junto a um grupo de enfermeiros de uma instituição hospitalar. O referencial teórico foi elaborado a partir da proposta educativa de Freire, adotando-se, como caminho metodológico, a realização do círculo de reflexão-ação, emergindo como temas: o desrespeito aos direitos dos trabalhadores; o desrespeito aos direitos dos clientes; e perspectivas de avanços a partir da prática educativa.
\end{abstract}

Palavras chave: Direitos do cliente, ética, problematização.

\section{SUMARY}

Through the notification of day-by-day practice of multiple situations regarding customer's rights disrespect, a support practice has been developed aiming to problematize customer's rights, among a group of nurses of a medical institution. The theoretical reference was created from Freire's educational proposal, having as a methodological path the fulfillment of reflection-action circle, being as themes: workers' rights disrespect; customers' rights and advanced perspectives from the educational practice.

Keywords: Customers' rights, ethics, problematization.

\section{RESUMEN}

A partir de la constatación en la práctica cotidiana de múltiples situaciones de falta de respeto a los derechos del cliente, se desarrolló una práctica educativa con el objetivo de cuestionar los derechos del cliente, junto a un grupo de enfermeros de una institución hospitalaria. El referencial teórico fue elaborado a partir de la propuesta educativa de Freire, adoptándose como camino metodológico la realización del círculo de reflexión-acción, surgiendo como temas: la falta de respeto a los derechos de los trabajadores, la falta de respeto a los derechos de los clientes y perspectivas de avances a partir de la práctica educativa.

Palabras claves: Derechos del cliente, ética, problematización.

Recepcionado: 7.03.2002. Aceptado: 17.06.2003.

\footnotetext{
*Enfermeiro, Mestre em Enfermagem, Professor da Universidade Regional Integrada do Alto Uruguai e das Missões - URI- Santo Ângelo - RS - Brasil.

**Enfermeira, Doutora em Enfermagem, Professora Adjunto IV do Departamento de Enfermagem da Fundação Universidade Federal do Rio Grande - FURG - Pesquisadora do CNPq.
} 


\section{INTRODUÇÃO}

A realização deste estudo constituiu-se numa possibilidade de buscar respostas a algumas inquietações e inconformismos sentidos ao longo de nossa trajetória profissional. Constatamos, no ambiente hospitalar, que o atendimento aos clientes parece uma prática, predominantemente, curativa, fragmentada e influenciada pela filosofia da instituição que ainda prioriza as funções administrativas do enfermeiro em detrimento das de gerenciamento da assistência e das funções assistenciais.

Como enfermeiros, percebemos a baixa expectativa do cliente de compreender seu processo saúde-doença e de ter seus direitos à saúde respeitados. Eles parecem desconhecer seus direitos às informações que deveriam receber durante sua internação hospitalar, mostrando-se pouco questionadores (1). A equipe parece se mostrar incomodada quando o cliente reivindica seus direitos, rotulando-o, por vezes, de "cliente chato". Perguntamo-nos, então, até que ponto o exercício da sua cidadania pode estar sendo confundido com manifestação de "chatice" por parte do cliente.

Abordando, especificamente, o atendimento de enfermagem, nas instituições hospitalares, percebemos muitas situações que podem ser caracterizadas de desrespeito aos direitos do cliente como as decorrentes da falta de recursos humanos para seu atendimento (2). Por outro lado, as instituições têm justificado o quadro reduzido de funcionários, na área da enfermagem, como medida de economia hospitalar, permanecendo um aparente silêncio, aceitação e conformismo dos enfermeiros que atuam nessas unidades. Perguntamo-nos se esse aparente conformismo resulta de um temor dos enfermeiros de enfrentarem quem representa o poder, ou se existe uma acomodação do profissional com a situação enfrentada, tendo desistido da luta por melhores condições para prestar a assistência aos clientes.

Partindo, pois, do nosso desconhecimento de como os enfermeiros vêm enfrentando os direitos dos clientes no seu cotidiano, das estratégias que estão sendo adotadas, optamos por desenvolver este estudo com o objetivo de construir um processo educativo de problematização dos direitos do cliente junto a um grupo de enfermeiros de uma instituição hospitalar, tendo em vista a sua conscientização como profissional de enfermagem.

\section{A ASSIMETRIA PRESENTE NA RELAÇÃO ENTRE O PROFISSIONAL DA SAÚDE E O CLIENTE}

Apesar dos avanços na área do diagnóstico e do tratamento, relações mais simétricas entre clientes, profissionais da saúde e instituições, parece-nos ainda não terem avançado suficientemente. São muitas as situações do cotidiano profissional que demonstram uma relação, predominantemente autoritária, paternalista e de obediência. A cidadania pressupõe igualdade de direitos, implica uma relação recíproca de respeito aos direitos e deveres entre os cidadãos e o Estado. A participação dos envolvidos nesse espaço pode significar a redistribuição dos direitos a todos, evitando a transformação do outro em objeto (3).

O profissional, freqüentemente, de posse da informação, do conhecimento técnico-científico, tem exigido obediência, por parte dos clientes, para suas prescrições e orientações, visando à modificação de seus hábitos, como aparente pré-requisito para melhorar e assegurar a sua saúde (4). Diversos fatores, então, têm contribuído para manter o cliente numa relação de dependência para com o profissional da saúde: a falta de informação sobre seu próprio processo saúde-doença; as diferenças de linguagem entre o cliente e o profissional, sem que seja feito um esforço mais significativo, por sua parte, no sentido de modificar esta relação assimétrica; a estrutura organizacional das instituições de saúde, dentre outros (5).

Na prática, percebemos que, muitas vezes, informações vêm sendo sonegadas por 
profissionais, envolvidos em múltiplos afazeres, exercendo funções que, necessariamente, não são suas, alegando não dispor de tempo suficiente, ou, quem sabe, não priorizando esse momento de interação, de troca de experiências e de informações (2). Por outro lado, o saber do cliente sobre si, sobre sua vida, seu modo de se cuidar, seu problema vivido, freqüentemente, também, não tem encontrado espaço para ser veiculado, seja por "falta" de tempo, de interesse, de reconhecimento do seu valor e importância.

No entanto, a sociedade, como um todo, parece que vem se preocupando e começa a questionar-se quanto ao seu papel como clientes e consumidores dos serviços de saúde e, através de alguns movimentos, vem tentando defender seus direitos. No Brasil, dentre outros, a criação do Código de Defesa do Consumidor significou um avanço, pois estabelece normas de proteção e defesa do consumidor, de ordem pública e social. O código prevê, ainda, aspectos que devem ser observados quanto à qualidade de produtos e serviços, bem como a prevenção e reparação de danos causados ao consumidor, através da responsabilização do profissional e/ ou da instituição que forneceu tal serviço (6).

\section{A PROBLEMATIZAÇÃO DA PRÁTICA COTIDIANA COMO UMA NECESSIDADE ÉTICA}

O ser humano é um ser único, com capacidade de refletir, de reconhecer-se como sujeito histórico; capaz de agir e reagir conscientemente sobre a realidade, estabelecendo relações com a mesma, com outros sujeitos e com outros grupos sociais (7).

Como sujeito histórico, age conforme suas concepções morais tendo como base seus valores e crenças. A moral pode ser compreendida como princípios, valores e normas que regem o agir humano nas suas diferentes relações sociais, considerando o momento histórico vivido (8). Já, a ética pode ser entendida como um dos mecanismos de regulação das relações sociais dos seres hu- manos. Compreende a noção de autonomia individual, reflexão crítica, problematização, indagação de questões relativas ao comportamento humano do ponto de vista do certo e errado, almejando sempre o bem estar dos sujeitos, sem ser prescritiva, normatizadora (8). A ética problematizadora consiste na problematização das práticas usuais, bem como na apresentação de uma proposta alternativa, toda vez que as práticas atuais se mostrarem inadequadas (9).

A problematização significa a ação de refletir intencionalmente sobre o que se diz, o que se faz, o que se percebe, o que se é, buscando compreender o porquê das coisas e das ações, o para quê delas. Já a conscientização pode ser entendida como o processo que oportuniza ao ser humano descobrir-se, perceber-se oprimido e / ou opressor, não se conformando com a situação vivida, buscando, através da ação, modificar sua relação com outros sujeitos, consigo mesmo e com o mundo (10).

Aética problematizadora pretende que os valores e as normas sejam examinados e questionados; as práticas cotidianas, analisadas, com a participação de todos os envolvidos em vez de apenas legitimar as práticas usuais (9). Na área da enfermagem especificamente, profissionais vêm focalizando a questão da ética e, na ética, os direitos do cliente abordando tais temas sob diferentes ângulos. Germano constata que o ensino da ética na enfermagem, devido às circunstâncias histórico-sociais, tem assumido uma postura conservadora, não-reflexiva, numa visão a-histórica marcada por uma ética pautada no conformismo, na docilidade e na obediência às determinações superiores (5).

Aparentemente, não há um suficiente questionamento por parte dos enfermeiros quanto ao exercício de sua prática, da ordem estabelecida, ou seja, o perguntar-se para quem tem servido tais práticas: a quem interessa manter essa situação de prática não reflexiva, de alienação, de exercício de poder? É preciso destacar que, cada vez mais, os enfermeiros preocupados e inconformados com este processo de "coisificação" das pessoas, 
tanto dos clientes como, possivelmente de si próprios, por se sentirem impotentes para alcançar maiores rupturas neste vivido, têm optado por direcionar seu olhar crítico, investigador e de estudo para o cotidiano de sua prática. Tais exercícios têm se feito numa tentativa de apontar possibilidades de uma mudança como estratégias de fortalecimento de uma categoria profissional comprometida consigo e com os direitos daqueles que buscam os seus cuidados.

\section{TRAJETÓRIA METODOLÓGICA}

Para a construção desta prática educativa, adotamos a proposta pedagógica libertadora e problematizadora de Paulo Freire, constituindo um grupo de reflexão-ação, aos moldes do círculo de cultura, em que os participantes, em círculo, dialogam, refletem, trocando saberes, ensinando e aprendendo juntos, construindo modos coletivos de pensar e de agir, a partir de temas geradores propostos pelo grupo frente aos objetivos do trabalho (10). A pedagogia de Freire transcende os limites da educação enquanto disciplina social, podendo ser entendida como uma forma de ler o mundo, na tentativa de sua transformação, através da ação consciente (11). Em sua proposta, teoria e prática caminham juntas e unidas num ato dialético e político do saber, sendo ensinadas e aprendidas, formando uma práxis dialética com vistas à conscientização, gerando a transformação (7).

$\mathrm{O}$ estudo desenvolveu-se num hospital geral de um município do Estado do Rio Grande do Sul, Brasil, nos meses de junho e julho de 1998 através da realização de oito encontros, já acordados desde a proposta inicial, e no mês de maio de 1999, quando realizamos mais dois encontros. Foram convidados informalmente todos os 25 enfermeiros que se encontravam trabalhando na instituição, nos turnos manhã e tarde, apresentando-se os objetivos do trabalho e a metodologia proposta. Oito enfermeiros aceitaram o convite, compondo o grupo que se reunia na própria instituição, uma vez por semana, no próprio horário de trabalho.

No primeiro encontro, solicitamos o Consentimento Livre e Esclarecido dos participantes, apresentando, novamente, os objetivos do trabalho e sua proposta, de maneira que os sujeitos compreendessem e atuassem como co-construtores do conhecimento, numa relação de troca, a partir de suas vivências e reflexões, suas "formas de ler o mundo", tendo como foco a questão de como vinha se dando o respeito aos direitos dos clientes, no contexto de sua própria atividade profissional, refletindo-a, criticando-a, com vistas a nela implementar mudanças. Assim, a partir dos temas geradores e dos sub-temas que emergiam, era realizada uma leitura tanto política quanto lingüística da realidade, com vistas a seu desvelamento crítico e transformação.

A coleta dos dados efetivou-se através de anotações no diário do pesquisador, gravação em fita magnética, constituindo-se, fundamentalmente, no registro de termos mais significativos, manifestações, reflexões, reações e expressões, percebidas nos participantes. Ao término de cada encontro, procedíamos à complemementação dos dados e a sua análise inicial, organizando-os de modo a apresentá-los ao grupo no encontro seguinte para sua validação. A devolução dos dados ao grupo favorecia o processo de problematização, pois permitia a continuidade das discussões, com vistas à conscientização dos enfermeiros tendo em meta o respeito aos direitos dos clientes.

Os encontros tinham uma duração prevista de uma hora, porém, estendiam-se, às vezes, até duas horas, conforme a necessidade, interesse e disponibilidade do grupo em participar das discussões. Conforme a necessidade do grupo, eram realizadas leituras para subsidiar as discussões, utilizando-se textos que abordam questões como cidadania $(7,10)$, direitos do cliente $(1,6)$, ética profissional (12).

Nos primeiros encontros, as discussões focalizaram, principalmente, o desrespeito aos direitos dos próprios trabalhadores e suas 
repercussões para o respeito aos direitos dos clientes. Passada este fase inicial, aparentemente necessária de queixas individuais e coletivas sobre as precárias condições de trabalho vivenciadas, foram mais diretamente problematizados os direitos dos clientes, complementando oito encontros. Em 1999, retornamos à constituição do grupo numa tentativa de conhecer possíveis avanços construídos pelos enfermeiros no que se refere aos direitos dos clientes, a partir dos encontros já realizados préviamente

Assim, a partir da análise dos dados colhidos, consolidaram-se três grandes temas: Desrespeito aos direitos dos trabalhadores e, conseqüentemente aos direitos dos clientes; Desrespeito aos Direitos dos clientes; Perspectivas de avanços a partir da prática educativa, os quais são apresentados a seguir.

\section{DESRESPEITO AOS DIREITOS DOS TRABALHADORES E SUA RELAÇÃO COM O DESRESPEITO AOS DIREITOS DOS CLIENTES}

Sendo um dos principais problemas enfrentados em seu cotidiano, os participantes, aparentemente, necessitaram e preferiram abordar, inicialmente, as condições inadequadas de trabalho enfrentadas, como a rotineira falta de material, o que interfere no trabalho do enfermeiro. No entanto, isto parece ser contraditório, pois, institucionalmente, esta tem a "qualidade" como proposta administrativa, solicitando a participação dos trabalhadores no estabelecimento de metas para o próximo biênio. No entanto, os enfermeiros denunciam que as metas já estabelecidas, há dois anos atrás, em que requereram equipamentos e materiais, ainda não foram atendidas. Apesar de suas requisições, à coordenação de enfermagem e à administração superior, de mais recursos materiais e humanos para realização de seu trabalho, estas têm sido desconsideradas, como se não fizessem parte das condições indispensáveis à prestação da assistência.
Parece ser rotina, no seu cotidiano, a improvisação, o convívio "normal" com a precariedade de recursos materiais que, embora seja por eles percebido, não os têm levado a mobilizar-se, suficientemente, no sentido de mudança desta realidade. $\mathrm{O}$ enfermeiro tem priorizado a busca de materiais e/ou medicamentos a fim de executar suas atividades, em detrimento da realização de funções educativas, assistenciais e de gerenciamento da assistência (13).

Os enfermeiros parecem não reconhecer a necessidade de buscar outras estratégias. Não têm buscado compartilhar com os clientes, com outros membros da equipe de saúde ou, mesmo, de modo mais formal com as chefias e a administração, o esforço que vêm fazendo para conseguir melhores condições para atendimento dos clientes.

A enfermagem, muitas vezes, tem se mostrado passiva frente a quem representa o poder na instituição e, em muitos casos, é vista pela administração como exercida por profissionais cumpridores de ordens, demonstrando despreocupação com o seu trabalho, principalmente, quanto às condições oferecidas para que ele possa se realizar (14). A ética problematizadora, ao mesmo tempo que permite questionar a norma, seu cumprimento, sua pertinência ou não em relação à ética e à profissão leva à critica, também, da reprodução das relações de poder das classes dominantes (9).

É de entendimento dos participantes do grupo de Reflexão/ação que o enfermeiro tem a responsabilidade ética e legal de manter a privacidade do cliente, além de prestarlhe uma assistência livre de riscos físicos e morais, mas reconheceram, também, que, muitas vezes, outros fatores, independentes de suas vontades, podem influenciar na qualidade da assistência prestada. Os enfermeiros, ao agirem de forma passiva, sem um estranhamento da prática cotidiana, parece que perderam a capacidade de indignação frente à situação vivida, aparentemente acomodados, não visualizando suficientes perspectivas de mudança. 
Na condição de animadores dos debates, trouxemos para reflexão que tanto o Conselho Regional de Enfermagem (COREn), fiscalizador do exercício da enfermagem, como o Conselho Municipal de Saúde (CMS), são dois órgãos para os quais podem ser direcionadas as reivindicações e reclamações acerca das condições inadequadas de trabalho que enfrentam para prestar a assistência aos clientes. Por outro lado, os enfermeiros parecem demonstrar descrédito em relação aos efeitos práticos das denúncias realizadas:

o COREn não tem fiscalizado ou quando fiscaliza parece que não vê como problema essas questões levantadas, ou senão, conversa uma coisa com a enfermeira da unidade e com a administração resolve outra. Pelo que se sabe, essa situação vem acontecendo em outros hospitais também. Por que então eu vou me envolver, senão, vai sobrar para mim, sobra mesmo e eu preciso do emprego.

Uma outra questão levantada referiu-se a como os enfermeiros vêm fazendo tais solicitações de material à administração. Têm sido persistentes em suas reivindicações, argumentando, por escrito, sobre os prejuízos ao cliente em decorrência da falta de condições materiais, ou seus pedidos estão sendo feitos de forma verbal, sem documentação comprovatória e maior argumentação? E a utilização de estratégias coletivas, como tem se dado?

Podemos perceber, por outro lado, que ter comadre individual e/ ou condições adequadas para sua desinfecção, assim como biombos para assegurar a privacidade dos clientes, pode ser entendido como uma questão que ultrapassa apenas à questão referente à provisão de material adequado para o exercício da assistência de enfermagem, constituindo-se numa questão ética, no reconhecimento do cliente, da sua condição de sujeito.

Com o objetivo, então, de reconhecer e respeitar esta condição do cliente como sujeito, questionamos se não seria necessário que ele próprio, por outro lado, fosse informado da inexistência de biombos em quantidade suficiente na instituição para resguar- dar sua privacidade, assim como do número insuficiente de comadres, de modo a que pudesse compreender a distância entre o que é oferecido à clientela e o que deveria receber. Não seria necessário informá-lo, ainda, que é seu direito poder negar-se a receber assistência em tais condições? Neste sentido, à medida que assim o fizermos, estaremos reconhecendo sua autonomia, possibilitando o exercício da sua cidadania.

Todavia, a atitude mais comum adotada pelos enfermeiros, frente às condições inadequadas de trabalho, tem sido o não esclarecimento do cliente, a defesa da instituição, o não questionamento das irregularidades, talvez, por temor de represálias por parte da administração hospitalar. O seu aparente silêncio, a omissão das informações aos clientes representam uma conduta ética equivocada, corporativa, favorecendo não aos direitos dos clientes, mas aos interesses institucionais e profissionais (4).

À medida que o enfermeiro assumir o seu dever de esclarecer o cliente em relação aos seus direitos, incentivando-o a exercer e reconhecer sua cidadania, poderá, dessa forma, concomitantemente, provocar mudanças em si, em sua prática profissional, na assistência como um todo, uma vez que mudanças podem se dar a partir de pequenas transformações, de pequenas rupturas.

O grupo externalizou sua preocupação frente ao reduzido número de elementos da equipe de enfermagem para o atendimento aos clientes, bem como o também reduzido número de enfermeiros. Esta deficiência de recursos humanos resulta em sobrecarga de trabalho aos integrantes da equipe de enfermagem que, muitas vezes, não conseguem dar conta das múltiplas atividades a serem desempenhadas no seu turno de trabalho.

À medida que a equipe for insuficiente para o atendimento aos clientes, haverá um maior desgaste físico, insatisfação, cansaço, aumento do stress. Ainda, pôde se evidenciar a ocorrência de sentimento de culpa, nos enfermeiros, pelas ações que não puderam realizar; além de ficarem mais expostos a erros, mesmo que involuntários, com riscos a 
saúde e à segurança do cliente. Podemos perceber, então, que a atuação dos enfermeiros pode estar sendo realizada com transgressões ao próprio Código de Ética dos Profissionais de Enfermagem que, em seu artigo 17, determina como responsabilidade do enfermeiro que avalie, de modo criterioso, sua competência legal, assumindo atribuições para as quais reconhece capacidade de desempenho seguro tanto para si quanto aos clientes sob seu cuidado (12).

O reduzido número de funcionários, além de interferir no trabalho da equipe de enfermagem, atinge o cliente. À medida que lhe for dispensada menor atenção, seu atendimento poderá ser mais demorado, resultando em atraso ou na não realização de seus cuidados. Como conseqüência, o tratamento poderá ser menos eficiente, podendo significar, também, retardo em sua recuperação, com a necessidade de permanecer mais tempo internado com perdas, tanto para o cliente, como para sua família, assim como para a instituição e para a sociedade como um todo. Além destas conseqüências, a demora ou a não realização de determinados procedimentos podem ocasionar outros problemas não identificados ou percebidos apenas a longo prazo, diferentemente do que pode acontecer em decorrência da falta de um medicamento (13).

Não seria, então, nosso dever esclarecê-lo e a seus familiares acerca das condições em que está sendo atendido? Esclarecê-los, também, que é seu direito, garantido constitucionalmente, de reivindicar uma assistência de enfermagem preconizada pelo Sistema Único de Saúde, com eqüidade, integralidade de assistência, universalidade de acesso, direito à informação e à preservação da sua autonomia?

Os enfermeiros reconhecem que o cliente tem o direito de receber as informações necessárias durante sua hospitalização (12), mas referem que, muitas vezes, esse direito lhes é negado pelos próprios profissionais que os atendem, talvez, por medo de represália e de punição da instituição. Medo, também, de que o cliente se torne questionador e passe, de forma gradativa e crescente, a reivindicar seus direitos, mostrando-se, também, como um opressor. O enfermeiro, não podendo atendê-lo, enfrentaria outros conflitos, consigo mesmo, com o cliente e com a instituição:

Merece reflexão o fato de que os enfermeiros, agindo assim, passivamente, tenham perdido a capacidade de indignação. Tais práticas parecem ter se tornado usuais, não os surpreendendo ou os incomodando frente a situações concretas de desrespeito. Esta perda da capacidade de incomodação, de passividade, diante do vivido, pode representar não mais a sua vontade, mas sim a vontade da instituição, pois os oprimidos, como coisas, parecem não ter uma finalidade, assumindo, como suas, as finalidades determinadas por seus opressores (7).

O medo e a opressão foi outro problema que ficou bastante evidente e foi alvo de reflexões com o grupo. Os enfermeiros percebem-se oprimidos, por parte dos representantes da administração, especialmente quando esta não lhes oferece e parece não lhes possibilitar espaços para que reivindiquem melhores condições de trabalho e de atendimento ao cliente, assim como quando lhes exige que executem ações que podem extrapolar seus limites de competência, como responder por mais de uma unidade, no período diurno, ou das supervisoras noturnas que respondem por todo hospital, nesse período. Assumindo funções para as quais não se percebem preparados, os enfermeiros colocam em risco a segurança do cliente, bem como sua própria atuação enquanto enfermeiros, podendo, até, ser responsabilizados por imperícia conforme relato a seguir:

Quando eu estou na supervisão e às vezes me chamam na UTI, eu vou com o coração na mão, pois tem muitas coisas que não tenho experiência e tenho medo de fazer errado.

Ficou evidente, a limitação da autonomia profissional dos enfermeiros em sua prática cotidiana e que, por vezes, estes reproduzem com os clientes, com os membros de suas 
equipes de enfermagem, esta relação de poder e dominação que sofrem por parte da instituição, assim como do médico. Nestas condições, a ética profissional também pode estar representada por uma ética legitimadora (9), pois a acomodação ao existente e a acriticidade parecem predominar. As práticas parecem determinar as normas morais, não havendo o questionamento, por parte dos enfermeiros, do porquê de ser assim, quem vem se beneficiado com tais práticas.

Associado ao medo e à opressão que os enfermeiros referem sofrer por parte da instituição, encontram-se os baixos salários percebidos pela equipe de enfermagem. Esta situação influencia no trabalho do enfermeiro, à medida que tem o atendimento de suas necessidades básicas comprometido.

\section{DESRESPEITO AOS DIREITOS DO CLIENTE}

Os enfermeiros relataram situações do seu cotidiano que podem ser caracterizadas como de desrespeito à autonomia do cliente, tais como a não solicitação do seu Consentimento Livre e Esclarecido, antes da realização de qualquer procedimento e atendimento; a decisão pelo cliente, sem consultá-lo, embora com a intenção de estar lhe "fazendo o bem", conforme afirmação a seguir:

a equipe geralmente só avisa ao paciente que vai realizar determinado procedimento, como, por exemplo, 'vamos fazer uma injeçãozinha' que o médico deixou; ou 'tá na hora do curativo'. Mas eu acho que devemos explicar o que ele está tomando, indagar se deseja fazer o curativo agora ou mais tarde; algumas vezes, eu explico para o que é a medicação que estou administrando ao paciente, mas às vezes, no correcorre, nem dá tempo para explicar seus efeitos aos pacientes.

O grupo, refletindo sobre suas atitudes como profissionais da saúde, reconheceu que os clientes vêm sendo desrespeitados ao não serem informados acerca dos procedimentos que neles poderão ser realizados, para que, de posse das informações, pudessem decidir submeter-se ou não ao tratamento e atendimento proposto. Afirmaram, ainda, que sempre que possível procuram orientar os clientes em relação a tais procedimentos, mas que não faz parte dos seus hábitos solicitarem autorização para a sua realização. Admitiram que, muitas vezes, o cliente sequer é orientado sobre a realização de determinado procedimento, pois a equipe, muitas vezes, negligencia esse cuidado.

Os profissionais verbalizaram que desconheciam a necessidade desta solicitação, antes da realização de determinados procedimentos e atendimento aos clientes. Desconheciam, também, a proposta de se aliarem ao cliente na luta por melhores condições de atendimento em saúde, como é enfatizado no Preâmbulo do Código de Ética dos Profissionais de Enfermagem (12). Este desconhecimento, segundo entendimento do grupo, pode decorrer, também, da ausência de discussão destas questões em seu ambiente de trabalho, o que poderia se dar se houvesse uma maior preocupação com a educação continuada na instituição.

Associado, ainda, ao desconhecimento do enfermeiro sobre o novo Código de Ética dos Profissionais de Enfermagem, poderia se questionar tanto o dever quanto a responsabilidades das instituições e das chefias de enfermagem, dos Conselhos Profissionais, assim como dos próprios profissionais, quanto ao acesso e informação dos avanços e inovações que vêm se dando na profissão. Parece que a ausência de reflexão, de discussão e de conhecimento das suas responsabilidades ético-legais, têm favorecido à equipe de saúde transgredir alguns direitos dos clientes.

Refletindo sobre a formação dos enfermeiros e sobre a nossa própria formação como alunos do curso de graduação e depois como profissionais, aprendemos e ensinamos que, para a realização de determinados procedimentos nos clientes, estes deveriam ser orientados, sendo explicado, previamente, o quê e o porquê da realização de tais procedimentos. Ingenuamente, pensávamos que apenas orientar o cliente seria suficiente para demos- 
trar o nosso respeito à sua autonomia. Hoje, percebemos e discutimos com o grupo que a autonomia do cliente ultrapassa o seu esclarecimento acerca dos procedimentos em si. O reconhecimento da sua autonomia requer que respeitemos o seu direito de decisão sobre sua pessoa, seu tratamento e seu bem estar; que solicitemos o seu consentimento livre e esclarecido para a realização de qualquer procedimento e/ ou tratamento e observemos a decisão do cliente em aceitar ou não se submeter aos mesmos (15). Geralmente, as decisões são tomadas pela equipe, na crença de que sabem mais e que, portanto, podem escolher o que é melhor para o cliente. O enfermeiro, muitas vezes, ao exercer essa atitude paternalista em relação ao cliente, está violando sua autonomia.

O grupo reconheceu que os valores pessoais e as crenças dos clientes devem ser respeitados, sendo necessário esclarecê-los, assim como seus familiares, dos possíveis benefícios, riscos e conseqüências decorrentes da assistência de enfermagem. Entretanto, para que a nossa prática de enfermagem se faça de modo diferente, faz-se necessário que problematizemos as relações que vimos mantendo com o cliente, tornando-as abertas, horizontais, dinâmicas, amadurecidas e de mútua responsabilidade, mediante a qual, o cliente possa sair de uma posição de objeto em que é infantilizado, tornando-se um cidadão com capacidade de decidir, de opinar conscientemente acerca dos assuntos que dizem respeito a si (1).

Merece reflexão a questão de que o saber do cliente sobre seu corpo, sobre o seu problema de saúde vivido, freqüentemente, não tem sido objeto do diálogo, da interação, talvez, por falta de interesse, de tempo ou do reconhecimento, pelo enfermeiro, de seu valor e importância para o cliente. Do ponto de vista ético, prestar as informações ao cliente vai além das exigências do próprio Código de Ética dos Profissional de Enfermagem; significa reconhecer no cliente sua condição de sujeito com direitos e deveres, o qual necessita da informação para poder decidir sobre sua saúde, seu bem estar, seu corpo.
Ao não reconhecerem a importância da informação, do diálogo, os profissionais da saúde estão negando aos clientes, conforme nos diz Freire (7), o seu direito de pronunciar-se e de expressar o mundo, de expressarem não só o significado da doença para si, mas a sua percepção da realidade vivida. Segundo os enfermeiros, em face do elevado número de atividades desenvolvidas pela equipe, parece não "sobrar tempo" ou, parece não ser reconhecido como prioridade dialogar, esclarecer, orientar, educar o cliente e sua família, enfim, respeitar sua condição de cidadão.

A despersonalização do cliente pode ser entendida como uma situação de desrespeito aos seus direitos à medida que é tratado como coisa, como objeto a mercê do cuidado dos profissionais da saúde. Os clientes, muitas vezes, são vistos de modo generalizado e tratados como mais um "caso" ou mais um "número" por parte da equipe de enfermagem:

A discriminação dos clientes pode ser vivenciada nos serviços de saúde, existindo uma desigualdade de acesso, especialmente, para os clientes do sistema público, iniciando-se nos serviços mais simples aos mais especializados. Em relação à assistência de enfermagem, os participantes deixam transparecer que não existe diferença no atendimento, de pacientes privados aos do serviço público, em relação a capacitação profissional, exceto pelo diferente número de profissionais para seu atendimento, sendo geralmente maior nas unidades privadas, do que nas dos outros clientes, o que pode diferenciar a assistência de enfermagem prestada.

\section{PERSPECTIVAS DE AVANÇOS A PARTIR DA PRÁTICA EDUCATIVA}

Buscamos verificar, junto ao grupo, alguns indicadores de mudança na sua ação que pudessem ser entendidos como sinalizadores de um processo de conscientização, pois ele acontece a partir do ato de reflexão sobre a 
ação desenvolvida e, quanto mais conscientizados, mais poderemos desvelar a realidade em que estamos imersos, tornando-a cognoscível pela sua análise consciente, em busca de uma outra ação.

A partir dos encontros nos grupos de reflexão/ação, os enfermeiros passaram a se reconhecer imersos em uma relação de dominação, de sujeição, que parecia, antes, despercebida e, até, negada. Apesar de tal dominação vir se reproduzindo, dia a dia, o grupo não pareceu manifestar perspectivas de mudança nessa relação. Parece que os enfermeiros têm evitado o enfrentamento das relações de poder, o que os têm mantido na condição de oprimidos, sujeitando-se a essa força opressora, a qual quem ousa desafiar, pode, até, sofrer o castigo da censura e da demissão.

Além da ameaça do desemprego, outra questão que pode ser considerada como impeditiva para que os enfermeiros busquem mudanças em sua prática, é o medo do conflito e a sua dificuldade para enfrentá-lo. No entanto, é necessário o estranhamento, a ruptura desta relação de dominação, seja através da solidariedade, do fortalecimento do grupo de enfermeiros, como, também, a partir da problematização de sua prática cotidiana, podendo, ao se reconhecerem como sujeitos oprimidos, serem capazes de oferecer resistência, de se libertarem da dominação em que estão imersos.

Ao sujeitar-se à situação de opressão, de dominação, de poder, aceitando passivamente atuar em condições inadequadas de trabalho, o enfermeiro está sendo desrespeitoso não só consigo mesmo, mas com o cliente, oferecendo-lhe inadequadas condições de atendimento, desrespeitando, assim, seu direito a um atendimento com qualidade. $\mathrm{O}$ enfermeiro pode, até, optar por sujeitar-se a atuar em condições inadequadas de trabalho, mas isto não lhe dá o direito a oferecer, em decorrência desta opção, uma assistência de enfermagem inadequada aos clientes.

No entanto, constatamos manifestações de enfermeiros que já questionam esta postura passiva, mostrando-se mais críticos frente a esta atitude, reconhecendo ser necessário uma mudança nessa relação, mesmo que ainda incipiente, mas que pode ser fortalecida com a adesão de outros membros da equipe de enfermagem e mesmo do cliente. Estas mudanças, mesmo que tímidas, podem ser o início de um processo mais amplo, no qual o respeito aos direitos e à autonomia do cliente sejam mais efetivos.

Pelas verbalizações acontecidas no grupo de Reflexão/ação, podemos perceber que os enfermeiros continuam assumindo, para si, responsabilidades que seriam de outros profissionais, como do médico, do farmacêutico, da nutricionista, assoberbando-se ainda mais de atividades, deixando, com isto, de realizar funções assistenciais e de gerenciamento da assistência exclusivamente suas. Apesar da opressão e do medo da demissão, alguns membros da equipe já vêm refletindo e questionando o porquê da realização, pela enfermagem, de atribuições de outros profissionais. Podemos perceber, ainda, algumas estratégias que vêm sendo por eles utilizadas para a não realização de ações que competem a outros profissionais, mesmo que isto implique em sua demissão da instituição pela administração.

A sujeição a quem representa o poder hegemônico na instituição, ao médico, às chefias, foi reconhecido pelos membros do grupo. Entretanto, outros sinalizadores de microrrupturas em busca de uma transformação na prática dos enfermeiros puderam ser observados. Estas microrrupturas, assim como as suas múltiplas possibilidades, puderam ser constatadas, pela busca, por parte de alguns dos seus integrantes, de Cursos de Especialização, problematizando a sua prática profissional, através do desenvolvimento de atividades, envolvendo a equipe do seu local de trabalho, numa tentativa de alcançar mudanças no seu cotidiano de trabalho.

Percebemos, através das manifestações, que o grupo se sentia mais unido e fortalecido em suas decisões, tanto que houve sugestões de continuarem a se reunir regularmen- 
te, bem como convidar outros membros para se agregarem ao grupo, com a finalidade de problematizarem suas questões cotidianas na instituição. Outro avanço que pôde ser percebido, no grupo de reflexão/ação, foi em relação ao reconhecimento da autonomia, do direito do cliente à informação.

Apoiados em Freire, podemos refletir acerca das pequenas mudanças que vêm ocorrendo nas ações dos enfermeiros, pois o homem é quem faz a história, transforma o mundo através de suas ações, e a conscientização apenas acontece mediante a práxis, através da ação e da reflexão (10), implicando em uma nova ação, agora mais crítica da realidade do sujeito.

Entendemos como necessário diante das falas dos enfermeiros, refletir acerca das atitudes assumidas pelas chefias de enfermagem que, freqüentemente, também como oprimidas, não têm buscado aliar-se aos profissionais na busca de melhores condições de trabalho.

\section{CONSIDERAÇÕES FINAIS}

Esta prática educativa teve como objetivo problematizar, com um grupo de enfermeiros, a questão dos direitos dos clientes, permitindo-nos verificar como percebem e vêm enfrentando, em seu cotidiano, as situações em que se evidenciam relações de desrespeito aos direitos do cliente, tendo em vista a sua conscientização como profissionais de enfermagem. Permitiu-nos, também, verificar como eles percebem e vêm enfrentando as questões relacionadas ao desrespeito de seus próprios direitos enquanto trabalhadores da saúde, problematizando não só tais situações de desrespeito a si, mas, também, as conseqüências negativas para os clientes. A partir dos diálogos acontecidos no grupo, pudemos conhecer algumas das suas opiniões, crenças e valores; como o grupo pensa e age, em sua prática cotidiana, no enfrentamento destas questões.

Acreditamos ser necessário mudar esta relação, reconhecendo-se o cliente como sujeito de sua própria vontade, do seu próprio cuidado, com direitos e deveres, enfim, um cidadão. É necessário, também, que construamos uma relação simétrica, democrática, com o cliente, uma relação de mutualidade, com respeito e responsabilidades recíprocas, de aprendizado, de respeito à sua historicidade e unicidade.

Os enfermeiros, a partir da problematização e discussões ocorridas no grupo de reflexão, parecem ter se permitido questionar a situação que estão vivenciando como profissionais e a assistência de enfermagem prestada aos clientes. Essa reflexão de como vem sendo sua prática, possibilitou-nos visualizar alguns avanços em relação ao respeito aos direitos do cliente, como o reconhecimento da necessidade de solicitação do seu Consentimento Livre e Esclarecido antes de nele realizar determinados procedimentos e tratamento; o direito do cliente à informação; a necessidade de considerar a sua vontade, respeitando, assim, sua autonomia.

A conscientização como profissional de enfermagem é um processo que pode ser lento, com avanços e retrocessos. A partir da reflexão dos enfermeiros sobre o seu fazer, através de pequenas mudanças em sua ação, podemos chegar à mudança da prática cotidiana. Entendemos que é fundamentalmente a partir da reflexão sobre o seu vivido, que cada indivíduo procurará ou não se comprometer com a transformação da realidade. As reflexões acontecidas, os questionamentos, a participação ativa e o interesse demonstrado pelos participantes foram capazes de impulsionar o grupo para avançar em sua busca de "ser mais" em sua prática, sendo, assim, educadores de si e de outros sujeitos e, por conseguinte, possíveis agentes de transformação. 


\section{REFERÊNCIAS BIBLIOGRÁFICAS}

1. GAUDERER, E. C. (1995). Os direitos do paciente: um manual de sobrevivência. $5^{\circ}$ ed. Rio de Janeiro: Record.

2. SELLI, L. (1998). Bioética na enfermagem. São Leopoldo: Ed. da UNISINOS.

3. BERTASO, J. M. (1998). Devir-cidadania: as (im) possibilidades na leitura freudiana. Florianópolis. UFSC. Dissertação (Mestrado em Ciências Humanas, Direito) - Universidade Federal de Santa Catarina.

4. LUNARDI, V. L. (1997). Do poder pastoral ao cuidado de si: a governabilidade na enfermagem. Florianópolis: Tese (Doutorado) Programa de PósGraduação em Enfermagem, Universidade Federal de Santa Catarina.

5. GERMANO, R.M A (1993). Etica e o ensino de ética na enfermagem do Brasil. São Paulo: Cortez.

6. BRASIL (1998). Código de proteção e defesa do consumidor: Lei $n^{\circ} 8.078 / 90$. São Paulo. Saraiva.

7. FREIRE, P. (1987). Pedagogia do oprimido. 21. ed. Rio de Janeiro: Paz e Terra.

8. FORTES, P. A. de C. (1998). Ética e saúde. São Paulo: E.P.U.
9. ANDERY, A. A. (1985). Três modalidades de ética profissional. IN: Queiroz, J.J. A ética no mundo de hoje. São Paulo: Paulinas, p. 75-87.

10. FREIRE, P. (1980). Conscientização: teoria e prática da libertação uma introdução ao pensamento de Paulo Freire. São Paulo: Moraes.

11. SAUPE, R. y col. (1997). Concepções do educador Paulo Freire: como vem sendo utilizadas pela enfermagem. Revista Cogitare Enfermagem, Curitiba: 2 (1):70-75.

12. BRASIL, Resolução COFEN n ${ }^{\circ} 160$ de 12 de janeiro de 1993, Aprova o Código de Ética dos Profissionais de Enfermagem. República Federativa do Brasil, Brasília.

13. LUNARDI FILHO, W. D. (1998). O mito da subalternidade do trabalho da enfermagem à medicina. Florianópolis, Tese (Doutorado). Universidade Federal de Santa Catarina, UFSC.

14. SANTOS, S. R. dos; FILHO, J.R. (1995). Enfermagem: fator de satisfação. Revista Brasileira de Enfermagem. Brasília: 48(3): 242-250.

15. CLOTET, J.; GOLDIN, J. R.; FRANCISCONI, C. F. (2000). Consentimento informado e a sua prática na assistência e pesquisa no Brasil. Porto Alegre: EDIPUCRS. 